\title{
A Qualitative Exploration of Seriously III Patients' Experiences of Goals of Care Discussions in Australian Hospital Settings
}

\author{
Moira O'Connor, $P h D^{7}$, Kaaren J. Watts, $P h D^{7}$ (D), Warren D. Kilburn, MEd\&DevPsych ${ }^{2}$, \\ Kitty Vivekananda, $P h D^{3}$, Claire E. Johnson, $P h D^{4,5,6}$ (D), Sharon Keesing, $P h D^{7}$, \\ Georgia K. B. Halkett, PhD ${ }^{8}$, Josephine Shaw, MPsych', \\ Valerie Colgan, MSc (Nurse Education) ${ }^{9}$, Kevin Yuen, MBBS, FAChPM ${ }^{10}$, \\ Renate Jolly, BSC (Nursing) ${ }^{17}$, Simon C. Towler, FCICM, FANZCA, FACHSM, FAMA 12,13,14, \\ Anupam Chauhan, MBBS MD FCICM ${ }^{15}$, Margherita Nicoletti, MBBS, FAChPM ${ }^{16}$, and \\ Anton D. Leonard, MB BCH BAO BA MPhil FCICM FANZCA MRCPI ${ }^{17}$
}

\begin{abstract}
'WA Cancer Prevention Research Unit, School of Psychology, Faculty of Health Sciences, Curtin University, Perth, WA, Australia; ${ }^{2}$ School of Psychological Sciences, Faculty of Education, Monash University, Melbourne, VIC, Australia; ${ }^{3}$ Counselling \& Psychology Programs, Faculty of Education, Monash University, Melbourne, VIC, Australia; ${ }^{4}$ School of Nursing and Midwifery, Faculty of Medicine, Nursing and Health Sciences, Monash University, Melbourne, VIC, Australia; ${ }^{5}$ Eastern Health, Melbourne, VIC, Australia; ${ }^{6}$ Medical School, Faculty of Health and Medical Sciences, The University of Western Australia, Perth, WA, Australia; ${ }^{7}$ School of Occupational Therapy, Social Work, and Speech Pathology, Faculty of Health Sciences, Curtin University, Perth, WA, Australia; ${ }^{8}$ School of Nursing, Midwifery and Paramedicine, Faculty of Health Sciences, Curtin University, Perth, WA, Australia; ${ }^{9}$ WA Cancer and Palliative Care Network, WA Department of Health, Perth, WA, Australia; ${ }^{10}$ Palliative Care Department, Royal Perth Bentley Group, East Metropolitan Health Service, Perth, WA, Australia; ${ }^{11}$ Respiratory Medicine, Royal Perth Bentley Group, East Metropolitan Health Service, Perth, WA, Australia; ${ }^{12}$ Intensive Care Unit, Fiona Stanley Hospital, South Metropolitan Health Service, Perth, WA, Australia; ${ }^{13}$ DonateLife, WA, MHPHDS Division, North Metropolitan Health Service, Perth, WA, Australia; ${ }^{14}$ End-of-Life Care, WA Department of Health, Perth, WA, Australia; ${ }^{15}$ Department of Intensive Care Medicine, Rockingham Hospital, South Metropolitan Health Service, Perth, WA, Australia; ${ }^{16}$ Palliative Care, Rockingham Hospital, South Metropolitan Health Service, Perth, WA, Australia; ${ }^{17}$ Intensive Care, Royal Perth Bentley Group, East Metropolitan Health Service, Perth, WA, Australia.
\end{abstract}

BACKGROUND: Goals of care (GOC) is a communication and decision-making process that occurs between a clinician and a patient (or surrogate decision-maker) during an episode of care to facilitate a plan of care that is consistent with the patient's preferences and values. Little is known about patients' experiences of these discussions.

OBJECTIVE: This study explored patients' perspectives of the GOC discussion in the hospital setting.

DESIGN: An explorative qualitative design was used within a social constructionist framework.

PARTICIPANTS: Adult patients were recruited from six Australian hospitals across two states. Eligible patients had had a GOC discussion and they were identified by the senior nurse or their doctor for informed consent and interview.

APPROACH: Semi-structured individual or dyadic interviews (with the carer/family member present) were conducted at the bedside or at the patient's home (for recently discharged patients). Interviews were audio-recorded and transcribed verbatim. Data were analysed for themes.

KEY RESULTS: Thirty-eight patient interviews were completed. The key themes identified were (1) values and expectations, and (2) communication (sub-themes: (i) facilitators of the conversation, (ii) barriers to the conversation, and (iii) influence of the environment). Most

Electronic supplementary material The online version of this article (https://doi.org/10.1007/s11606-020-06233-y) contains supplementary material, which is available to authorized users.

Received March 2, 2020

Accepted September 10, 2020

Published online October 9, 2020 patients viewed the conversation as necessary and valued having their preferences heard. Effective communication strategies and a safe, private setting were facilitators of the GOC discussion. Deficits in any of these key elements functioned as a barrier to the process.

CONCLUSIONS: Effective communication, and patients' values and expectations set the stage for goals of care discussions; however, the environment plays a significant role. Communication skills training and education designed to equip clinicians to negotiate GOC interactions effectively are essential. These interventions must also be accompanied by systemic changes including building a culture supportive of GOC, clear policies and guidelines, and champions who facilitate uptake of GOC discussions.

KEY WORDS: goals of care; communication; preferences; patients; internal medicine.

$\mathrm{J}$ Gen Intern Med 35(12):3572-80

DOI: $10.1007 / \mathrm{s} 11606-020-06233-y$

(c) Society of General Internal Medicine 2020

$\mathrm{H}$ ealth care systems face a paradox ${ }^{1}$ whereby advances in medical technology mean that life can be prolonged. ${ }^{2}$ Yet, seriously ill patients and their family members frequently prefer comfort care rather than aggressive interventions, ${ }^{1,3}$ 
although there are cultural variations. ${ }^{4}$ Doctors tend to prioritise longevity ${ }^{2}$ with the exception of palliative care providers whose focus is comfort and symptom control, ${ }^{5}$ and patients often continue to receive medical interventions as they approach end-of-life ("EOL")., ${ }^{3,6,7}$ The outcomes for seriously ill patients who undergo interventions (e.g. cardiopulmonary resuscitation ("CPR")) are frequently poor. ${ }^{8}$ Survival after discharge for patients who undergo in-hospital CPR ranges from 0 to $32 \%$, with rates declining with increasing age. ${ }^{9,10}$

Goals of care (GOC) is a communication and decisionmaking process that occurs between a clinician and a patient (or surrogate decision-maker) to facilitate a medical care plan that is consistent with the patient's preferences and values in the event of clinical deterioration. ${ }^{11,12}$ The GOC process focuses on guiding current health care decisions during the episode of care ${ }^{13}$ including whether to utilise life-sustaining interventions. ${ }^{14}$ This differs from the advance care planning (ACP) process which focuses on preparing for future health care decisions when a person can no longer make these decisions themselves. ${ }^{13}$ The COVID-19 pandemic, where there is the potential for rapid clinical deterioration and respiratory complications, has highlighted GOC discussions as a priority for seriously ill patients. ${ }^{15}$ GOC discussions are associated with fewer aggressive interventions at $\mathrm{EOL}$ and greater quality of life. ${ }^{7,16-18}$

Despite benefits, there are numerous barriers to effective GOC discussions. ${ }^{19-22}$ Clinicians report patient and family members' difficulties with accepting a poor prognosis, misunderstanding the limitations and complexity of life-sustaining interventions, ${ }^{19,23}$ and resistance to addressing EOL issues. ${ }^{19,24,25}$ Physician-related barriers include a lack of communication skills, ${ }^{22}$ discomfort in discussing death and dying, ${ }^{24}$ and fear of causing distress. ${ }^{26}$ System-level barriers include time pressures, ${ }^{21,26}$ lack of quality professional mentorship, ${ }^{24,26}$ few guidelines on discussing EOL issues, ${ }^{24}$ and lack of training around communicating about EOL. ${ }^{21,24,26}$ These factors could explain why a recent Australian study found that only one-quarter of patients referred to the intensive care unit (ICU) had a documented GOC discussion. ${ }^{27}$

Previous research around GOC discussions has focused on the views of physicians and nurses ${ }^{19-21,23,24,26,28}$ rather than patients and carers. ${ }^{14}$ Studies that examined the views of patients and families have frequently used questionnaires. ${ }^{2,11,29-31}$ A previous study used a validated questionnaire in interviews with older patients and family members and identified five (of 11) key elements that participants ranked most important for inclusion in a GOC discussion: preferences for care, prognosis, values, fears or worries, and questions. ${ }^{11}$ However, we still lack in-depth knowledge about stakeholders' experiences of GOC discussions ${ }^{32}$ including how well patients are prepared for GOC, the preferred timing of GOC, and environmental factors. In Australia, national health care standards and hospital accreditation schemes now require GOC discussions as part of comprehensive patient care. $^{33,34}$ The importance of aligning medical care with patients' values and preferences is also embedded in international health policies and standards. ${ }^{35,36}$ The current study was needed to explore how well the GOC process is working, and to identify areas for improvement. Specifically, this research aimed to explore patients' experiences of GOC discussions in the hospital setting. The study findings will inform the development of an educational intervention for hospital-based clinicians tailored to patients' needs.

\section{METHODS}

\section{Design}

A descriptive, exploratory qualitative design was adopted using a social constructionist framework ${ }^{37}$ which acknowledges the applied nature of the research and a focus on participants' views.

\section{Setting}

Participants were recruited from six hospitals in Western Australia and Victoria which had implemented the GOC process. The departments involved were ICU, respiratory medicine, renal medicine, general medicine, geriatric medicine, internal medicine, and orthopaedic surgery. Orthopaedic surgical patients were included because these individuals were elderly patients with hip fractures who were at high risk of surgical complications and/or mortality. ${ }^{38}$

\section{GOC Discussion and Form}

The usual practice is for the registrar or the consultant physician to conduct a GOC discussion with the patient and/or the carer, optimally within $48 \mathrm{~h}$ of admission. Discussions are initiated for patients who present for an episode of care who are at risk of clinical deterioration. A completed GOC form is placed in the patient's notes (Appendix 1). The form includes patient information (section 1); GOC and escalation plan (four options: all life-sustaining treatment; life-extending intensive treatment-with treatment ceiling; active ward-based treatment-with symptom and comfort care; and optimal comfort treatment-including care of the dying person) (section 2); summary of discussion (section 3); and extended use (section 4).

\section{Recruitment and Sampling}

A convenience sample of adult patients who had completed a GOC discussion in their current or recent episode of care in hospital was utilised. Inclusion criteria were aged 18 years or over, a GOC form and discussion completed, and able to communicate in English. Interviews were conducted until saturation was reached. These findings are part of a parent program of research exploring the experiences of stakeholders in GOC discussions (patients, carers, and health professionals). 


\section{Interviews}

Semi-structured interviews (individual, or dyadic with a family member/carer present) were conducted by authors $1,2,3$, 6 , and 8. All are experienced in sensitive interviewing and independent of the hospital setting. An interview schedule (Appendix 2) was developed by the research team and informed by the literature. ${ }^{11,26,28,39,40}$

\section{Procedure}

The researchers asked a senior nurse or the patient's doctor to identify eligible patients who had had a GOC discussion in their current or recent episode of care. The researcher approached the patient at the bedside or by telephone (for discharged patients), provided the study information sheet and consent form, and gave a verbal summary of the study. Written consent was obtained. Interviews were conducted at the bedside, or at the discharged patient's place of choice. Each interview was audio-recorded (range 8 to $38 \mathrm{~min}$ ) and transcribed verbatim.

\section{Data Analysis}

Transcripts were thematically analysed using Braun and Clarke's six phases of thematic analysis (Table 1). Thematic analysis enables a rigorous data-driven analysis. ${ }^{41} \mathrm{An}$ inductive approach ${ }^{42}$ was adopted. Authors 1 and 2 randomly selected four transcripts and coded these independently for initial concepts; they met to ensure consistency on the identified coding categories prior to author 2 coding the remaining transcripts. Authors 1, 2, 6, 8, 9, and 15 regularly discussed emerging themes and examples; any disagreements were resolved by consensus discussion, as per usual practice. ${ }^{43,44}$

\section{Quality}

Authors 1 and 2 led the analysis of the transcripts; the other authors contributed to interpretation. Nine coding categories were identified and from these, two over-arching themes and three sub-themes emerged (see Fig. 1). The consolidated criteria for reporting qualitative research (COREQ) checklist was used. $^{45}$

Table 1 Braun and Clarke's Six Phases of Thematic Analysis ${ }^{41}$

\begin{tabular}{|c|c|c|}
\hline Phase & Title & Description \\
\hline $\begin{array}{l}\text { Phase } \\
1\end{array}$ & Familiarisation & $\begin{array}{l}\text { Immersion and familiarisation with } \\
\text { the data through repeated reading }\end{array}$ \\
\hline $\begin{array}{l}\text { Phase } \\
2\end{array}$ & Coding & $\begin{array}{l}\text { Generation of initial codes by } \\
\text { systematically identifying and } \\
\text { labelling interesting features of the } \\
\text { data }\end{array}$ \\
\hline $\begin{array}{l}\text { Phase } \\
3\end{array}$ & $\begin{array}{l}\text { Searching for } \\
\text { themes }\end{array}$ & $\begin{array}{l}\text { Sorting the codes into themes and } \\
\text { extracting representative data }\end{array}$ \\
\hline $\begin{array}{l}\text { Phase } \\
4\end{array}$ & Reviewing themes & Review and refinement of themes \\
\hline $\begin{array}{l}\text { Phase } \\
5\end{array}$ & $\begin{array}{l}\text { Defining and } \\
\text { naming themes }\end{array}$ & $\begin{array}{l}\text { Defining the essence of each theme } \\
\text { and naming them }\end{array}$ \\
\hline $\begin{array}{l}\text { Phase } \\
6\end{array}$ & Writing the report & $\begin{array}{l}\text { Producing the final themes and } \\
\text { writing a narrative }\end{array}$ \\
\hline
\end{tabular}

Ethics approval for this study was obtained from the relevant institutional Human Research Ethics Committees (EC00270) and (HRE2018-0404).

\section{RESULTS}

\section{Participant Characteristics}

Forty-nine interviews were initiated with patients, with 38 included in the final data set (Table 2). The median time between the GOC discussion and the interview was 3 days (range 0 to 29 days). Participant characteristics are provided in Table 3; patients' self-reported medical conditions are summarised in Table 4.

Two main themes were identified: values and expectations, and communication. Three sub-themes were identified within "communication": (i) facilitators of the conversation, (ii) barriers to the conversation, and (iii) influence of the environment. "M" and "F" denote male and female gender, respectively.

\section{Values and Expectations}

This theme centred on the importance of quality of life rather than longevity, having a sense of control, patients' comfort or discomfort discussing EOL issues, and family involvement in discussion of EOL preferences.

Most patients were aware of the seriousness of their condition, accepted that death was possible, and were comfortable with the idea of life-sustaining interventions being withheld if their condition deteriorated: I do not want to be resuscitated. If I'm going, let me go. (F1). They wanted life-sustaining interventions only if they could maintain a reasonable quality of life and some independence. Patients did not want their life prolonged if the likely outcome was poor function, impairment, or they perceived they would be a burden to others. Some patients said they were ready for death if it came, and that potentially futile medical and artificial interventions were unwelcome.

if it means you're going to be in hospital for years....with machines keeping you alive, then no, forget about it. (M2)

Most patients valued the opportunity to discuss their preferences and goals for care; for some, this was the first time they had been asked about these issues. Having a say and being heard was important, with some expressing feelings of control by being able to articulate what they wanted. Participants used terms such as "empowerment": It made me feel more empowered (F7), and being active rather than passive.

One patient suggested that stating preferences would reduce the burden of decision-making on others. 


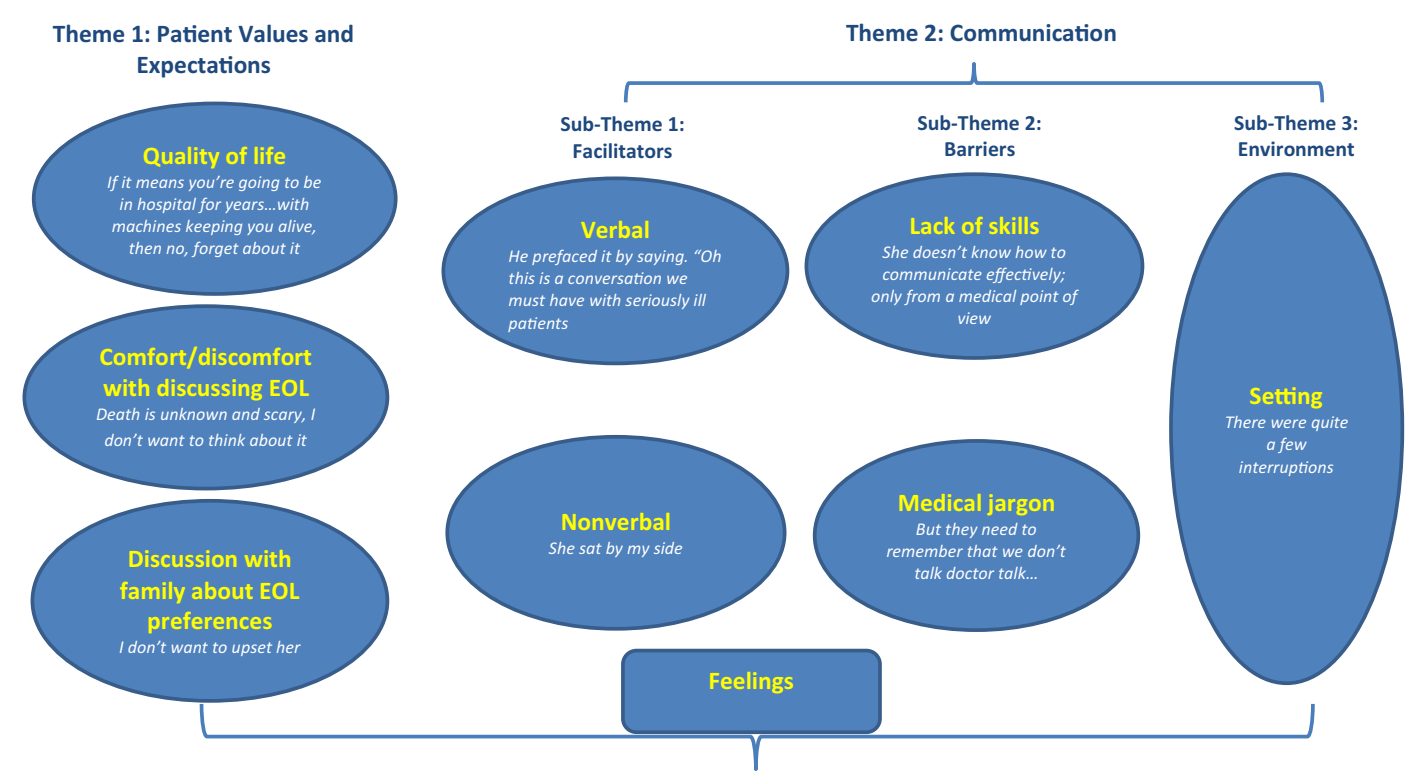

Figure 1 Visual representation of the nine coding categories, two themes, and three sub-themes that emerged from the patient data.

....other people need to know what you want. Otherwise, you're putting an unfair expectation on them.... (M2)

Several patients, however, stated they were not ready to die and would prefer to focus on living provided there was reasonable quality of life.

....if there's any possible way of being resuscitated and not a life-threatening hindrance to other people, I just want to keep going. (M3)

However, not all patients wanted the conversation. Some patients were not ready or comfortable with discussing EOL issues, they did not want to discuss death and dying, and they would have preferred not to have had the conversation. Not wanting to consider EOL was a major factor in this.

No, they didn't tell me what was going on, no I don't want to know, I'm too old now, and: they should ....not say anything. (F9)

Death is unknown and scary, I don't want to think about it. (F10)

Many patients reported that they had not talked with their family or general physician about EOL issues, despite the majority of patients being elderly and seriously ill: I do not .... want to upset her (F4). Several patients assumed that their family knew their preferences: I think she knows pretty well that I would not want to be kept alive - have something breathing for me. (F6).

Some patients who had tried to discuss EOL issues with family members said that the person was dismissive or had attempted to shut the conversation down suggesting family discomfort with or denial of the possibility of approaching death for their family member.

... they'll say, "Don't talk silly, Mum, you'll be here until you're a 100". (F5)

\section{Communication}

This theme centred on how the doctor's manner and communication style, and the setting influenced patients' perceptions of the discussion.

Facilitators of the Conversation. Many patients reported that the doctor(s) had a very positive approach. Patients who experienced the GOC interaction positively emphasised patient-centred elements of the discussion including normalising the topic, using non-verbal behaviours effectively, avoiding medical jargon, and spending time with the patient. Feeling "heard" and sensing that the doctor was listening and demonstrating understanding of their situation and preferences were very important to patients.

Introducing and normalising the discussion was experienced positively.

....he prefaced it by saying, "Oh this is a conversation we must have with seriously ill patients". (M11)

The discussion was also viewed positively by patients when the doctor used non-verbal behaviours to create rapport and

Table 2 Reasons for Discontinuation of Patient Interviews

\begin{tabular}{ll}
\hline \hline & $\boldsymbol{n = 1 1}$ \\
\hline Patient could not recall the goals of care discussion & 8 \\
Patient became distressed and did not wish to continue & 2 \\
Patient could not continue due to cognitive impairment & 1
\end{tabular}


Table 3 Patient Sample Characteristics $(N=38)$

\begin{tabular}{|c|c|c|}
\hline & Mean & SD \\
\hline Age (in years) & $\begin{array}{l}76.2^{\mathrm{a}} \\
N\end{array}$ & $\begin{array}{l}10.9 \\
\%\end{array}$ \\
\hline \multicolumn{3}{|l|}{ Gender } \\
\hline Female & 26 & 68 \\
\hline Male & 12 & 32 \\
\hline Other & - & - \\
\hline \multicolumn{3}{|l|}{ Country of birth } \\
\hline Australia & 20 & 53 \\
\hline Other & 18 & 47 \\
\hline \multicolumn{3}{|l|}{ Language spoken at home } \\
\hline English only & 34 & 90 \\
\hline Other & 4 & 10 \\
\hline \multicolumn{3}{|l|}{ Aboriginal or Torres Strait Islander } \\
\hline No & 37 & 97 \\
\hline Yes & 1 & 3 \\
\hline \multicolumn{3}{|l|}{ Employment } \\
\hline Currently employed & 1 & 3 \\
\hline Not currently employed & 3 & 8 \\
\hline Retired & 31 & 81 \\
\hline Household management & 1 & 3 \\
\hline Other & 2 & 5 \\
\hline \multicolumn{3}{|l|}{ Relationship status } \\
\hline Single & 1 & 3 \\
\hline Married/defacto or in a relationship & 21 & 55 \\
\hline Divorced or separated & 4 & 10 \\
\hline Widowed & 12 & 32 \\
\hline \multicolumn{3}{|l|}{ Residential location } \\
\hline Metropolitan area & 29 & 76 \\
\hline Regional area & 5 & 13 \\
\hline Rural or remote area & 3 & 8 \\
\hline Other (overseas) & 1 & 3 \\
\hline
\end{tabular}

${ }^{a}$ Age range 51-94 years

trust and to show that they were fully engaged in the conversation: ....she was human. (F12). This reflected a need to feel "human".

[The doctor] came very close to me and spoke to me....She wasn't rough or tough. She was a gentle lady. (F13)

She sat by my side (F13).

....he brings his stature to your level. So there's none of this standing over you. (F15)

Table 4 Summary of Patients' Self-Reported Medical Conditions $(N=34)$

\begin{tabular}{lll}
\hline \hline Description & $\boldsymbol{n}$ & $\boldsymbol{\%}$ \\
\hline Heart and circulatory disease & 11 & 29 \\
Lung and breathing difficulties $_{\text {Frailty and decline due to older age }}{ }^{\mathrm{a}}$ & 10 & 26 \\
Cancer & 8 & 21 \\
Infection (e.g. urinary tract infection; cellulitis) & 7 & 18 \\
Kidney disease & 5 & 13 \\
Progressive neurological condition & 2 & 5 \\
Dementia & 1 & 3 \\
Other conditions (e.g. infection, diabetes, osteoporosis, & 0 & 0 \\
& 10 & 26
\end{tabular}

anaemia)

Percentages total more $>100$ because some patients reported multiple medical conditions

Data was not available for 4 patients. ${ }^{a}$ Includes fractures post-fall
Patients appreciated a gentle, conversational style rather than being told what to do.

We just talked to each other, just person to person, that was very nice. (F14)

Time was considered important and most patients felt that the doctor spent enough time with them.

[I never] felt that he was rushed...YYou were his total focus until you had finished with him. (F15)

For most patients, the conversation was patient-driven and gave them a sense of a partnership and shared decision-making.

....together we did it....We got to the goal in the end.

(F17)

It was also helpful when the doctor used simple, clear language: I understood what he was getting at and what he was saying. (M11)

He used common language. We don't want technical I'm not in the medical profession. (F16)

Barriers to the Conversation. Several patients reported less positive experiences of GOC discussions because of the doctor's poor communication skills or inexperience; GOC interactions which were not patient-centred were associated with patient distress and dissatisfaction.

A failure by the clinician to build rapport during the conversation and failing to explore what was important to the patient was experienced negatively. This patient felt that the conversation was more about the doctor's agenda rather than focused on her needs and preferences.

....there is that kind of problem that she doesn't know me, she doesn't know my family, she doesn't know anything about me.... I don't think she was in tune enough....to have the conversation. It was quite hard...I felt like crying all the time.... (F19)

But it was what she wanted to say. Not what I wanted to say. (F19)

One patient did not feel her wishes were respected.

....no one took me seriously....the [specialist] said, "look, we've all just had lunch so I can assure you we won't be doing any extreme measures. We're too sleepy.”(F18) 
Several patients experienced an interaction where the doctor was sharp or dismissive. It's like you are not there, you are an invisible person. (F20)

.... I don't want to see this person. He was very abrupt, really full on and, you know. (F5)One patient said her doctor could not communicate effectively and this impaired her capacity to participate in the conversation, and another felt that his doctor was inexperienced.

She doesn't know how to communicate effectively; Only from a medical point of view. (F19)

No. I suspect she hadn't had a lot of experience at this sort of thing. (M2)

Several patients said the doctor used medical jargon which made understanding challenging.

...but they need to remember that we don't talk doctor talk and sort of explain in layman's terms, so you can understand things. (F21)

One patient reported the doctors had a very task-oriented approach, focused on the process and technology not her, such as recording the patient's information onto the computer.

... he's talking to you, but he's directing his remarks to him [the other doctor] and his computer. (F22)

Influence of the Environment. Not having a private, quiet place where the doctor and patient could have the discussion without interruption or background noise was experienced negatively. Whilst recognising the constraints of the hospital environment, patients wanted some privacy around and time for the conversation. One conversation was conducted in a corridor in the emergency department, which felt rushed with many distractions.

....there were nurses and everybody running all around but she sort of had me on a bed at the side ....I don't think there was [a curtain]. (F12)

Interruptions to the discussions were also common, which again was distracting and resulted in feelings of being unimportant.

There were quite a few interruptions. (F6)

\section{DISCUSSION}

This study explored seriously ill patients' perspectives of a GOC discussion during or soon after an episode of care in hospital. Two over-arching themes emerged from the patient transcripts: (1) values and expectations, and (2) communication.

Patients' willingness to engage in the conversation depended on how comfortable they were with death and dying, and whether they felt "ready to go". These views were embedded in a desire for quality of life including minimum suffering, maintaining a level of independence, and not burdening others. These values are consistent with those of studies where community samples rated dignity, avoidance of pain and suffering, remaining independent, ${ }^{2}$ and not being a bur$\operatorname{den}^{29}$ as the most important treatment goals. Key elements of the GOC discussion include exploring patients' values and asking about preferences for care in the event of clinical deterioration. ${ }^{11}$ The clinician needs to work collaboratively with the patient (and/or family) to explore preferences and develop a treatment plan that is respectful of, and responsive to, values. ${ }^{12}$ In relation to timing, previous research suggests it is better to initiate GOC early in a patient's episode of care. ${ }^{39}$ The doctor's clinical judgement alone is an unreliable trigger for GOC because clinicians frequently overestimate patients' prognosis. ${ }^{46}$ Clear guidelines about when and for whom the GOC process should be initiated need to be embedded within hospital policies and into communication skills training (CST) around GOC. Education around GOC for clinicians will need to cover more than just effective communication, but also when to initiate the conversation ${ }^{39}$ and how to create an appropriate setting. ${ }^{47,48}$

Most patients viewed the conversation as necessary despite the challenges. It gave them the opportunity to voice their preferences and a sense of control. These findings accord with previous research examining attitudes toward ACP where $91 \%$ of older individuals reported wanting to discuss EOL care. ${ }^{49}$ Many patients report they are comfortable with the topic and are willing to discuss EOL preferences, including life-sustaining treatments, if the doctor just asks them. ${ }^{30}$ Other research focussing on patient-centred care ${ }^{50}$ and patients' participation in health care decision-making ${ }^{51}$ has highlighted that providing patients with necessary information and involving them in decision-making increase feelings of empowerment. ${ }^{52,53}$ Some patients, however, reported feeling distressed and several patients did not want a conversation about death and dying. The GOC conversation requires a skilled clini$\operatorname{cian}^{54}$ to prepare patients and to navigate this interaction ${ }^{55}$ including responding to emotions expressed by patients and family members. ${ }^{56}$

How the clinician communicated during the GOC discussion appeared to influence whether the interaction was a positive or negative experience for patients and their overall satisfaction with the discussion. However, the reverse might also be true, that the clinician's communication is perceived more negatively if the patient is not ready or open to these discussions. Skilled communication and an interaction based upon trust where the clinician listens, builds rapport, and speaks honestly and sensitively with patients about death and 
dying are important to patients and family members/ carers. $^{29,54}$ Treating patients with respect and humanity; providing emotional support including compassion, hope, and comfort; and being sensitive to cues from the patient ${ }^{24,54}$ are also critical elements of effective communication. These elements align with Epstein and Street's model of communication in cancer care ${ }^{53}$ which describes the core functions of patient-centred interactions as fostering a good patientclinician relationship; information exchange; responding to emotions; managing uncertainty; decision-making; and enabling patient self-management. Their model also highlights the importance of the clinician's use of non-verbal behaviours to demonstrate an orientation toward the patient of genuine care and interest. ${ }^{53}$ This model could be a useful way of guiding conversations in this space together with the REMAP (reframe, expect emotion, map out patient goals, align with goals, propose a plan) framework for GOC discussions. ${ }^{53,56}$

Physicians, junior doctors, and nurses frequently report they feel ill-equipped to have GOC conversations because they lack formal training in communication skills regarding EOL care. $^{23,24,48}$ Providing physicians with access to CST early in their medical career ${ }^{53}$ and in-house to facilitate access is key to effective GOC discussions. ${ }^{57}$ CST programs for health professionals are associated with improvements in communication skills, particularly interventions that adopt an experiential approach and utilise role-play to practice skills learned. ${ }^{58,59}$ Several patients reported the doctor used medical jargon during the GOC conversation which may have compromised the patients' understanding. One study reported junior doctors frequently used jargon in a simulated patient-doctor encounter, ${ }^{60}$ and a further study reported radiation therapists used various types of medical jargon in their patient education sessions. ${ }^{61}$ Effective GOC discussions need simple, jargonfree language ${ }^{53}$; analogies to convey complex information; repetition ${ }^{61}$; and patients reflecting in their own words. ${ }^{62}$

There were challenges during the GOC discussion in relation to a lack of privacy, interruptions, and the doctor having limited time. Large patient volumes, ${ }^{47,49}$ crowding in emergency departments, ${ }^{63}$ a focus on technology and efficiency, and spatial layouts in hospital departments do not support privacy, ${ }^{47}$ and are barriers to effective communication. These findings suggest that creating a sense of space, time, and privacy should be addressed in GOC training and education. ${ }^{47}$ Organisations that are promoting GOC discussions need to ensure that appropriate time and suitable spaces for these interactions are made available.

\section{Future Research}

A research priority is the development and evaluation of CST targeted at equipping clinicians to conduct effective GOC discussions where there is immediate feedback given. ${ }^{58}$ Evaluations should include objective measures of the effectiveness and impact of CST programs such as videoing in situ GOC discussions between the treating team, patients, and family members, pre-and post-training. Whilst it was beyond the scope of the current research, future studies could examine how different patient characteristics (e.g. age, gender, medical issues) and contextual factors influence patients' experiences of GOC discussions. The perspectives of family and nonfamily carers and health professionals, focussed on their experiences of the GOC process, also require further exploration.

\section{Limitations}

Patients who declined to participate may have been less willing to discuss their experiences of the GOC discussion or they may have differed from the participants in other ways, such as being more unwell or less comfortable with death and dying. Three interviews were brief but were retained because they contained valuable information. The patient sample was predominantly female and Anglo Celtic, so the findings may not reflect male views and those of culturally diverse patients. The study was also based upon retrospective reports of patients' experiences which may be influenced by recall bias. However, most interviews occurred within one week of the patient having the GOC conversation so this likely enhances the integrity of the findings.

\section{CONCLUSIONS}

Many patients were willing to engage in a conversation about treatment goals and EOL wishes. When the conversations were patient-centred and conducted in a clear, empathic way, patients were satisfied and the experience was perceived as positive. When the conversations were conducted in a rushed manner or the physician was dismissive, the experience was negative with people feeling fearful and invisible. Privacy was important to patients and they disliked interruptions. Physicians need to ensure some level of privacy and be "present" even when time poor. Patients' values and expectations set the stage for goals of care discussions; however, the clinician's communication style and the environment play an important role.

At the individual level, CST for GOC discussions is needed using a range of strategies. Training should include ways of managing the environment to create privacy even in a busy ward. Organisational level changes should centre on providing in-house training for health professionals, sensitive to patients' needs. Systemic changes are also important and include building a culture of promoting and normalising discussions around GOC, clear policies and guidelines, and using champions to encourage uptake of GOC discussions.

Acknowledgements: We gratefully acknowledge the efforts of Jayamini Jayawardene and Shi Lee in interviewing patients. We also extend our gratitude to the many nurses and doctors who made it possible to identify and to approach eligible patients at each hospital site. We thank all of the patients who took part in this study. 
Corresponding Author: Moira O'Connor, $\mathrm{PhD}$; WA Cancer Prevention Research Unit, School of Psychology, Faculty of Health SciencesCurtin University, Perth, WA, Australia (e-mail: m.oconnor@curtin.edu. au).

Funding This research was funded by a grant received from the Royal Perth Hospital Medical Research Foundation.

\section{Compliance with Ethical Standards:}

Written consent was obtained. Ethics approval for this study was obtained from the relevant institutional Human Research Ethics Committees (ECOO270) and (HRE2018-0404).

Conflict of Interest: $M$ O'Connor, KJ Watts, CE Johnson, $G K B$ Halkett, $V$ Colgan, $K$ Yuen, $R$ Jolly, and $A D$ Leonard were coinvestigators on the grant received from the Royal Perth Hospital Medical Research Foundation. The remaining authors have no conflicts of interest to declare.

\section{REFERENCES}

1. Heyland DK, Barwich D, Pichora D et al. Failure to engage hospitalized elderly patients and their families in advance care planning. JAMA Intern Med 2013;173(9):778-87. doi: https://doi.org/10.1001/jamainternmed. 2013.180.

2. Milnes S, Corke C, Orford N, Bailey M, Savulescu J, Wilkinson D. Patient values informing medical treatment: a pilot community and advance care planning survey. BMJ Support Palliat Care 2019;9(3):e23. doi: https://doi.org/10.1136/bmjspcare-2016-001177.

3. Heyland D, Cook D, Bagshaw SM et al. The very elderly admitted to ICU: a quality finish? Crit Care Med 2015;43(7):1352-60. doi: https://doi.org/ 10.1097/CCM.0000000000001024.

4. Wicher CP, Meeker MA. What influences African American end-of-life preferences? J Health Care Poor Underserved 2012;23(1):28-58. doi:https://doi.org/10.1353/hpu.2012.00275.

5. Pastrana T, Jünger S, Ostgathe C, Elsner F, Radbruch L. A matter of definition-key elements identified in a discourse analysis of definitions of palliative care. Palliat Med 2008;22(3):222-32.

6. Teno JM, Gozalo PL, Bynum JP et al. Change in end-of-life care for Medicare beneficiaries: site of death, place of care, and health care transitions in 2000, 2005, and 2009. JAMA. 2013;309(5):470-7. doi: https://doi.org/10.1001/jama.2012.207624.

7. Hui D, Con A, Christie G, Hawley PH. Goals of care and end-of-life decision making for hospitalized patients at a Canadian tertiary care cancer center. J Pain Symptom Manage 2009;38(6):871-81. doi: https:// doi.org/10.1016/j.jpainsymman.2009.05.017.

8. Gershengorn HB, Li G, Kramer A, Wunsch H. Survival and functional outcomes after cardiopulmonary resuscitation in the intensive care unit. J Crit Care. 2012;27(4):421.e9-17. doi: https://doi.org/10.1016/j.jcrc. 2011.11.001.

9. Mallikethi-Reddy $\mathbf{S}$, Briasoulis A, Akintoye $\mathbf{E}$ et al. Incidence and survival after in-hospital cardiopulmonary resuscitation in nonelderly adults: US Experience, 2007 to 2012. Circ Cardiovasc Qual Outcomes 2017;10(2): e003194. doi: https://doi.org/10.1161/CIRCOUTCOMES. 116.003194

10. Stapleton RD, Ehlenbach WJ, Deyo RA, Curtis JR. Long-term outcomes after in-hospital CPR in older adults with chronic illness. Chest. 2014;146(5):1214-1225. doi: https://doi.org/10.1378/chest.13-2110.

11. You JJ, Dodek $\mathbf{P}$, Lamontagne $\mathbf{F}$ et al. What really matters in end-of-life discussions? Perspectives of patients in hospital with serious illness and their families. CMAJ. 2014;186(18):E679-87. doi: https://doi.org/10. 1503/cmaj. 140673.

12. Secunda K, Wirpsa MJ, Neely KJ et al. Use and Meaning of "Goals of Care" in the Healthcare Literature: a Systematic Review and Qualitative Discourse Analysis. J Gen Intern Med 2020;35(5):1559-66. doi: https:// doi.org/10.1007/s11606-019-05446-0
13. Myers J, Cosby R, Gzik D et al. Provider tools for advance care planning and goals of care discussions: A systematic review. Am J Hosp Palliat Med 2018;35(8):1123-32. doi: https://doi.org/10.1177/1049909118760303

14. Sinuff T, Dodek $\mathbf{P}$, You JJ et al. Improving end-of-life communication and decision making: the development of a conceptual framework and quality indicators. J Pain Symptom Manage 2015;49(6):1070-80. doi: https://doi.org/10.1016/j.jpainsymman.2014.12.007.

15. Curtis JR, Kross EK, Stapleton RD. The Importance of Addressing Advance Care Planning and Decisions About Do-Not-Resuscitate Orders During Novel Coronavirus 2019 (COVID-19). JAMA. 2020;323(18):17711772. doi: https://doi.org/10.1001/jama.2020.4894

16. Bischoff KE, Sudore R, Miao Y, Boscardin WJ, Smith AK. Advance Care Planning and the Quality of End-of-Life Care in Older Adults. J Am Geriatr Soc 2013;61(2):209-14. doi: https://doi.org/10.1111/jgs. 12105.

17. Hartog CS, Peschel I, Schwarzkopf D et al. Are written advance directives helpful to guide end-of-life therapy in the intensive care unit? A retrospective matched-cohort study. J Crit Care 2014;29(1):128-33. doi: https://doi.org/10.1016/j.jcrc.2013.08.024.

18. Detering KM, Hancock AD, Reade MC, Silvester W. The impact of advance care planning on end of life care in elderly patients: randomised controlled trial. BMJ. 2010;340:c1345. doi: https://doi.org/10.1136/ bmj.c1345.

19. You JJ, Downar J, Fowler RA et al. Barriers to Goals of Care Discussions With Seriously Ill Hospitalized Patients and Their Families: A Multicenter Survey of Clinicians. JAMA Intern Med 2015;175(4):54956. doi: https://doi.org/10.1001/jamainternmed.2014.7732.

20. Ethier JL, Paramsothy T, You JJ, Fowler R, Gandhi S. Perceived Barriers to Goals of Care Discussions With Patients With Advanced Cancer and Their Families in the Ambulatory Setting: A Multicenter Survey of Oncologists. J Palliat Care 2018;33(3):125-142. doi: https:// doi.org/10.1177/0825859718762287.

21. Aslakson RA, Wyskiel R, Thornton I et al. Nurse-perceived barriers to effective communication regarding prognosis and optimal end-of-life care for surgical ICU patients: a qualitative exploration. J Palliat Med 2012;15(8):910-5. doi: https://doi.org/10.1089/jpm.2011.0481.

22. Visser M, Deliens L, Houttekier D. Physician-related barriers to communication and patient- and family-centred decision-making towards the end of life in intensive care: a systematic review. Crit Care 2014;18(6):604. doi: https://doi.org/10.1186/s13054-014-0604-z.

23. Aleksova N, Demers C, Strachan PH et al. Barriers to goals of care discussions with hospitalized patients with advanced heart failure: feasibility and performance of a novel questionnaire. ESC Heart Fail 2016;3(4):245-252.

24. Granek L, Krzyzanowska M, Tozer R, Mazzotta P. Oncologists strategies and barriers to effective communication about the end of life. J Oncol Pract 2013;9(4):e129-35. doi: https://doi.org/10.1200/JOP. 2012.000800.

25. Ceccarelli CM, Castner D, Haras MS. Advance care planning for patients with chronic kidney disease - why aren't nurses more involved? Nephrol Nurs J 2008;35(6):553-7.

26. Waldron N, Johnson CE, Saul $\mathbf{P}$ et al. Development of a video-based education and process change intervention to improve advance cardiopulmonary resuscitation decision-making. BMC Health Serv Res 2016;16(1):555. doi: https://doi.org/10.1186/s12913-016-1803-x

27. Orford NR, Milnes SL, Lambert $\mathbf{N}$ et al. Prevalence, goals of care and long-term outcomes of patients with life-limiting illness referred to a tertiary ICU. Crit Care Resusc 2016;18(3):181-8.

28. Robinson CA, Fyles G, McKenzie M. Oncologist experience implementing goals of care discussions in everyday ambulatory oncology practice: Implications for education. J Cancer Educ 2017;32(2):301-307. doi: https://doi.org/10.1007/s13187-015-0915-z.

29. Steinhauser KE, Christakis NA, Clipp EC, McNeilly M, McIntyre L, Tulsky JA. Factors considered important at the end of life by patients, family, physicians, and other care providers. JAMA. 2000;284(19):2476-82.

30. Simon J, Porterfield P, Bouchal S, Heyland D. 'Not yet' and 'Just ask': barriers and facilitators to advance care planning - a qualitative descriptive study of the perspectives of seriously ill, older patients and their families. BMJ Support Palliat Care 2015;5(1):54-62. doi: https://doi.org/ 10.1136/bmjspcare-2013-000487

31. Curtis JR, Engelberg RA, Nielsen EL, Au DH, Patrick DJ. Patientphysician communication about end-of-life care for patients with severe COPD. Eur Respir J 2004;24(2):200-5 
32. Johnson CE, Chong JC, Wilkinson A, Hayes B, Tait S, Waldron N. Goals of patient care system change with video-based education increases rates of advance cardiopulmonary resuscitation decisionmaking and discussions in hospitalised rehabilitation patients. Intern Med J 2017;47(7):798-806.

33. Australian Government [Internet]. 2019; Accessed at Australian Government at https://www.safetyandquality.gov.au/standards/nsqhs-standards on 14 May 2020.

34. Australian Commission on Safety and Quality in Health Care (ACSQHC) [Internet]. 2019; Accessed at ACSQHC at https://www.safetyandquality. gov.au/standards/national-safety-and-quality-health-service-nsqhsstandards/assessment-nsqhs-standards/australian-health-service-safety-and-quality-accreditation-scheme on 26 May 2020.

35. National Institute for Health and Care Excellence (NICE) [Internet]. 2020; Accessed at NICE at https://www.nice.org.uk/guidance/NG56/chapter/ Recommendations\#principles-of-an-approach-to-care-that-takes-account-of-multimorbidity on 26 May 2020.

36. Institute of Medicine (US) Committee on Quality of Health Care in America. Crossing the Quality Chasm: A New Health System for the 21st Century. Washington (DC): National Academies Press; 2001.

37. Burr V. Social Constructionism. 3rd ed. Abingdon: Taylor \& Francis; 2015.

38. Kata A, Cenzer I, Sudore RL, Covinsky KE, Tang VL. Advance Care Planning Prior to Death in Older Adults with Hip Fracture. J Gen Intern Med 2020. doi: https://doi.org/10.1007/s11606-020-05644-1

39. Gieniusz M, Nunes R, Saha V, Renson A, Schubert FD, Carey J. Earlier Goals of Care Discussions in Hospitalized Terminally Ill Patients and the Quality of End-of-Life Care: A Retrospective Study. Am J Hosp Palliat Med. 2016;35(1):21-7. https://doi.org/10.1177/1049909116682470

40. Peereboom K, Coyle N. Facilitating goals-of-care discussions for patients with life-limiting disease-communication strategies for nurses. J Hosp Palliat Nurs 2012;14(4):251-8. https://doi.org/10.1097/ NJH.Ob013e3182533a7f

41. Braun V, Clarke V. Using thematic analysis in psychology. Qual Res Psychol 2006;3(2):77-101.

42. Patton MQ. Qualitative evaluation and research methods. 2nd ed Thousand Oaks: Sage Publications; 1990.

43. McDougall E, O'Connor M, Howell J. "Something that happens at home and stays at home": An exploration of the lived experience of young carers in Western Australia. Health Soc Care Community. 2018;26(4):572-80. https://doi.org/10.1111/hsc. 12547

44. Bradbury-Jones C. Enhancing rigour in qualitative health research: exploring subjectivity through Peshkin's I's. J Adv Nurs 2007;59(3):290-8.

45. Tong A, Sainsbury P, Craig J. Consolidated criteria for reporting qualitative research (COREQ): a 32-item checklist for interviews and focus groups. Int $\mathrm{J}$ Qual Health Care 2007;19(6):349-57

46. Christakis NA, Smith JL, Parkes CM, Lamont EB. Extent and determinants of error in doctors' prognoses in terminally ill patients: prospective cohort study. BMJ. 2000;320(7233):469-73.

47. Merchant S, O'Connor M, Halkett G. Time, space and technology in radiotherapy departments: how do these factors impact on patients' experiences of radiotherapy? Eur J Cancer Care (Engl). 2017;26(2). https://doi.org/10.1111/ecc. 12354

48. You JJ, Fowler RA, Heyland DK, on behalf of the Canadian Researchers at the End of Life Network (CARENET). Just ask: discussing goals of care with patients in hospital with serious illness. CMAJ. 2014;186(6):425-32. https://doi.org/10.1503/cmaj.121274

49. Sharp T, Moran E, Kuhn I, Barclay S. Do the elderly have a voice? Advance care planning discussions with frail and older individuals: a systematic literature review and narrative synthesis. Br J Gen Pract 2013;63(615):e657-68. doi: https://doi.org/10.3399/bjgp13X673667.

50. Delaney LJ. Patient-centred care as an approach to improving health care in Australia. Collegian. 2018;25(1):119-23. doi: https://doi.org/10. 1016/j.colegn.2017.02.005

51. Vahdat S, Hamzehgardeshi L, Hessam S, Hamzehgardeshi Z. Patient involvement in health care decision making: a review. Iran Red Crescent Med J 2014;16(1):e12454. doi: https://doi.org/10.5812/ircmj. 12454.

52. Sidani S, Epstein D, Miranda J. Eliciting patient treatment preferences: A strategy to integrate evidence-based and patient-centered care. Worldviews Evid-Based Nurs 2006;3(3):116-23.

53. Epstein R, Street RJ. Patient-Centered Communication in Cancer Care: Promoting Healing and Reducing Suffering Publication No. 07-6225. Bethesda: National Cancer Institute; 2007.

54. Curtis JR, Wenrich MD, Carline JD, Shannon SE, Ambrozy DM, Ramsey PG. Understanding physicians' skills at providing end-of-life care: perspectives of patients, families, and health care workers. J Gen Intern Med 2001;16(1):41-9.

55. Cummings A, Lund S, Campling N, May CR, Richardson A, Myall M. Implementing communication and decision-making interventions directed at goals of care: a theory-led scoping review. BMJ Open 2017;7(10):e017056.

56. Childers JW, Back AL, Tulsky JA, Arnold RM. REMAP: a framework for goals of care conversations. J Oncol Pract 2017;13(10):e844-e50.

57. Bernacki RE, Block SD. Communication about serious illness care goals: a review and synthesis of best practices. JAMA Intern Med 2014;174(12):1994-2003. doi: https://doi.org/10.1001/jamainternmed. 2014.5271.

58. Kissane DW, Bylund CL, Banerjee SC et al. Communication skills training for oncology professionals. J Clin Oncol 2012;30(11):1242-7. doi: https://doi.org/10.1200/JCO.2011.39.6184.

59. Moore PM, Rivera S, Bravo-Soto GA, Olivares C, Lawrie TA. Communication skills training for healthcare professionals working with people who have cancer (Review). Cochrane Database Syst Rev. 2018(7):Art. No.: CD003751. doi:https://doi.org/10.1002/14651858.CD003751.pub4

60. Howard T, Jacobson K, Kripalani S. Doctor talk: Physicians' use of clear verbal communication. J Health Commun 2013;18:991-1001. doi: https://doi.org/10.1080/10810730.2012.757398.

61. Schnitzler L, Smith SK, Shepherd HL et al. Communication during radiation therapy education sessions: The role of medical jargon and emotional support in clarifying patient confusion. Patient Educ Couns 2017;100(1):112-120. doi: https://doi.org/10.1016/j.pec.2016.08.006.

62. Kripalani S, Weiss B. Teaching about health literacy and clear communication. J Gen Intern Med 2006;21(8):888-90.

63. Institute of Medicine Committee on the Future of Emergency Care in the United States Health System. Hospital-Based Emergency Care: At the Breaking Point. Washington, DC; 2006.

Publisher's Note Springer Nature remains neutral with regard to jurisdictional claims in published maps and institutional affiliations. 